\title{
Methods of treatment of pleural empyema in children
}

\author{
Roksana Barglik, Wojciech Korlacki, Andrzej Grabowski \\ Department of Children's Developmental Defects Surgery and Traumatology, School of Medicine with the Division \\ of Dentistry in Zabrze, Medical University of Silesia in Katowice, Poland
}

\section{ABSTRACT}

Pleural empyema is caused by the accumulation of purulent content in the pleural cavity. In recent years, a higher incidence of pleural empyema in children has been observed. Pleural empyema is usually caused by the passage of infection from inflamed pulmonary tissue. The appropriate medical imaging and laboratory tests, including microbiological examination of the pleural cavity contents, enable the initiation of proper methods of treatment. Depending on the clinical condition of the patient, variable methods of treatment are used, such as: antibiotic therapy with simultaneous systemic therapy, thoracentesis, pleural cavity drainage with optional intrapleural fibrinolysis, thoracoscopic debridement of the accumulated effusion and fibrin accumulation, as well as lung decortication via open surgery or by thoracoscopic technique.

\section{KEY WORDS:}

children, treatment, pleural empyema, thoracoscopy.

\section{INTRODUCTION}

Pleural empyema is the cause of hospitalisation of $0.6-3 \%$ of children [1]. Seventy per cent of cases are reported in infants and young children under four years of age [1]. The mortality rates due to pleural empyema in children stand at $8 \%[1,2]$.

The aim of the study is to discuss the pathophysiology, symptoms, diagnosis, and treatment of empyema in children, including current therapeutic trends and modern surgical techniques.

\section{DEFINITION AND CLASSIFICATION}

Pleural empyema (empyema pleurae) is an accumulation of purulent content within the pleural cavity $[1,3-5]$. The cause of this disease is usually the spread of inflammation from infected adjacent lung tissue $[1,3,6,7]$.

There are three stages of clinical progression of pleural empyema:
- stage I: exudative - in the case of contagion of effusion accumulated in the pleural cavity (1-4 days);

- stage II: fibrinopurulent - in which the purulent fluid, with a high content of polymorphonuclear cells and fibrin, accumulates in the pleural cavity. The presence of septations and loculations of the empyema is typical at this stage (5-14 days);

- $\quad$ stage III: the stage of the organisation of the empyema - pleural stratification becomes thicker and stiff, which causes a growing impairment of respiratory movements (2-4 weeks). In case of significant progression, massive pleural adhesions are formed (fibrothorax) $[1,3,5,8-10]$.

\section{ANATOMY AND PHYSIOLOGY OF THE PLEURA}

The pleura is a serous membrane covering the lung, consisting of two layers: the parietal pleura, which coats the inside of the chest, and the pulmonary pleura (also known as the visceral pleura) surrounding the surface of

\section{ADDRESS FOR CORRESPONDENCE:}

Roksana Barglik, Department of Children's Developmental Defect Surgery and Traumatology, School of Medicine with the Division of Dentistry in Zabrze, Medical University of Silesia in Katowice, 13-15 3 Maja St., 41-800 Zabrze, Poland, ORCID: 0000-0002-8057-9176, e-mail: roxi01@interia.pl 
the lung [11]. These two laminae enclose a narrow pleural cavity, which, under normal conditions, is a potential space [11]. At physiological condition, it contains only a few millilitres of serous fluid, the volume of which is defined as $0.1-0.2 \mathrm{ml} / \mathrm{kg}$ of body weight $[4,12]$. This fluid moistens the pleura and it allows pleural laminae to slide against each other without friction during breathing movements $[11,13]$.

\section{PATHOPHYSIOLOGY}

In the case of various disease processes, the production of the fluid may be increased or its absorption may be impaired $[4,9]$. Fluid accumulating in the pleura in the case of non-inflammatory diseases is called transudate (e.g. in the course of cardiovascular diseases, hypoproteinaemia, systemic diseases) $[4,5,6,9]$. Conversely, the fluid appearing in the pleural cavity as a result of inflammatory or cancerous processes is called exudate [4-6]. In the case of fluid accumulation in the pleural cavity, initially the main symptoms reported by the patient are chest pain, which increases during respiratory movements, and inconvenient cough $[1,6]$. As the volume of effusion increases, the pleural laminae spread out, which reduces pain. A rising volume of fluid causes also a progressive dyspnoea [6]. In the case of inflammatory processes, symptoms of the main disease coexist, such as high fever or productive cough with mucopurulent secretion $[1,6]$.

The most common cause of pleural empyema in children is the spread of infection by continuity from the infected lung, which is called pleuropneumonia $[1,3,6,7$, 9]. The less frequent causes include infection of initially sterile effusion or haemothorax, evacuation of the lung abscess to the pleural cavity, haematogenous infections, chest trauma, postsurgical complications or passage of an inflammatory process from the chest wall, subphrenic region, or mediastinum $[1,3,7]$.

Staphylococcus aureus, Streptococcus pneumoniae, Streptococcus pyogenes, Streptococcus milleri, and Haemophilus influenzae are the most common pathogens causing pleural empyema [14-18]. However, Gram-negative bacteria (Pseudomonas aeruginosa, Escherichia coli, Klebsiella pneumoniae, and Proteus spp.) predominate in hospital-acquired infections [14, 17].

\section{SYMPTOMS}

The increasing volume of effusion in the pleural cavity leads to lung compression, dyspnoea symptoms, and resulting respiratory failure $[1,4]$. Typical pleurisy symptoms are: pyrexia, cough, dyspnoea, chest pain increasing with breathing, tachycardia, and tachypnoea $[1,4,6]$.

\section{PHYSICAL EXAMINATION}

The accumulation of fluid in the pleural cavity gives symptoms such as:

- weakening or disappearance of voice tremor,

- $\quad$ suppression of percussion sound in the area occupied by the effusion,

- attenuation or elimination of respiratory noise [6].

In the initial period of inflammation, when the inflamed pleural layers rub against each other, pleural friction may be heard [6]. Rhonchi and crepitation caused by the main disease of the lung tissue or by atelectasis of the pulmonary parenchyma induced by its compression may be heard above the rest of the lung fields [6].

\section{DIAGNOSTICS OF PLEURAL EMPYEMA}

\section{MEDICAL IMAGING}

The basic diagnostic examination used in medical imaging in the case of suspected pleural empyema is chest radiograph in the posteroanterior projection and, in the case of diagnostic doubts, in the lateral projection $[1,4$, $9,19]$. Free fluid in the pleural cavity manifests as a homogeneous shading, starting from the lower parts of the lung, making a characteristic pattern according to the Ellis-Damoiseau line (Fig. 1A) [6]. The more accumulated the effusion, the greater the area of shading in the radiological image. It should be noted that X-ray shows the presence of fluid if its volume is greater than $200 \mathrm{ml}$ in the posteroanterior projection and $50 \mathrm{ml}$ in the lateral projection [12].

Diagnostic difficulties may occur in the case of isolated fluid accumulation in the interlobar fissure (interlobar pleuritis), between the base of the lung and the diaphragm (diaphragmatic pleuritis), and in the mediastinal pleura (mediastinal pleuritis). In ambiguous cases, the diagnosis can be confirmed by computed tomography, which allows accurate location of the accumulated fluid, estimation of its volume and density, and visualisation of septations and multiloculations of empyema $[1,4,9,20]$. Chest CT is also very useful for differential diagnosis with pulmonary inflammatory infiltration, pulmonary abscess, or pulmonary tumours. Currently, ultrasound diagnosis of the pleural cavity is appreciated $[4,6,14,19]$. Ultrasound allows us to detect effusion in a volume less than $100 \mathrm{ml}$, helps to precisely locate the effusion and assess the thickness of the fluid layer, and reveals the fibrin septations and empyema loculations $[4,6,14]$. Ultrasonography also allows for a controlled puncture of the pleural cavity $[1,4,6,14]$.

\section{LABORATORY TESTS}

In the abnormalities of the basic blood tests, leukocytosis with neutrocytosis, elevated erythrocyte sedimentation rate (ESR), and positive reactions to C-reactive pro- 

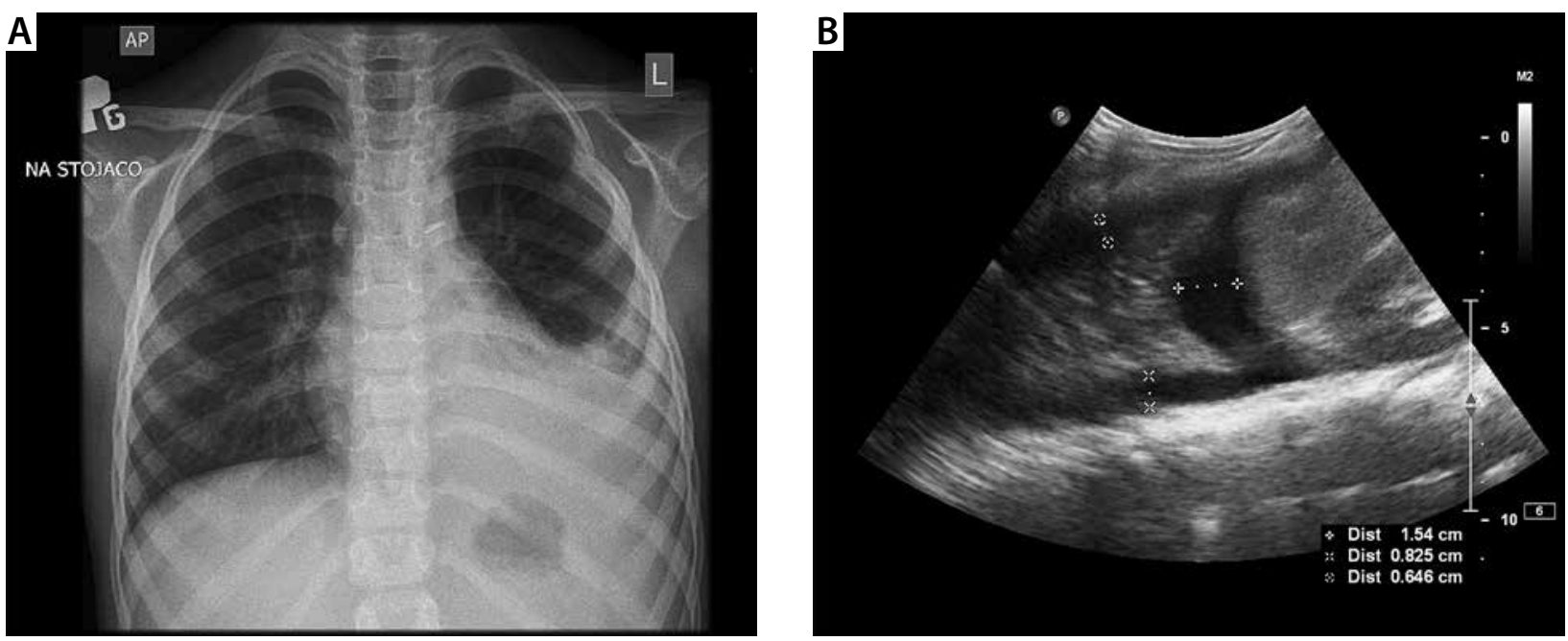

FIGURE 1. Medical imaging. A) Radiograph of the chest in the PA projection - effusion in the left pleural cavity. B) Ultrasound image of a left pleural cavity - free fluid over the hemidiaphragm

tein (CRP) are found, but these tests are not specific for this disease entity $[6,21]$.

\section{PLEURAL FLUID EXAMINATION}

Pleural fluid can be obtained by puncture of the pleural cavity, pleural drainage, or during surgery (thoracoscopy) $[13,14]$. During the preliminary macroscopic assessment, the colour and transparency of the effusion should be assessed [13]. Transudate fluid is yellow and clear, while the inflammatory exudate becomes cloudy. In the case of a severe stage of the inflammatory process, the exudative effusion takes on a purulent appearance - it is dense, cloudy, and cream-colored [12]. After preliminary macroscopic estimation, the obtained material should be relayed for biochemical and microbiological tests, and in the case of suspicion of a proliferative process it can be submitted for cytological examination [22].

\section{BIOCHEMICAL EXAMINATION}

Pleural fluid in its composition contains components similar to plasma, but in different, variable proportions. Depending on the biochemical composition, the pleural fluid is referred to as transudate or exudate $[4,6,9]$. The basic differentiating element is the concentration of protein - the exudate fluid contains $>3.5 \mathrm{mg} / \mathrm{dl}$, and the transudate fluid $<2.5 \mathrm{mg} / \mathrm{dl}[5,6,9,14]$. A more precise biochemical evaluation of pleural effusion is based on Light's criteria (Table 1) [22].

Biochemical examination of pleural fluid in the case of parapneumonic infection is highly relevant. In the early exudative stage the preponderance of neutrophils is observed, with glucose level in pleural fluid greater than $60 \mathrm{mg} / \mathrm{dl}, \mathrm{pH}$ above 7.20, and lactic acid dehydrogenase (LDH) less than three times above the upper limit of normal in serum (often < $1000 \mathrm{U} / \mathrm{l})$. In this stage parapneu-
TABLE 1. Light's criteria

\begin{tabular}{|l|}
\hline $\begin{array}{l}\text { A pleural effusion is probably exudative if at least one } \\
\text { of the following criteria exist }\end{array}$ \\
\hline The ratio of pleural fluid protein to serum protein is greater than 0.5 \\
\hline The ratio of pleural fluid LDH to serum LDH is greater than 0.6 \\
\hline $\begin{array}{l}\text { Pleural fluid LDH is greater than } 23 \text { times the normal upper limit } \\
\text { for serum }\end{array}$ \\
\hline
\end{tabular}

monic effusion is called "uncomplicated". Whereas in the fibrinopurulent stage, the parameters of the pleural fluid are changed - typically for this the stage glucose level is below $60 \mathrm{mg} / \mathrm{dl}, \mathrm{pH}$ is less than 7.20, and the pleural LDH level is more than three times over the upper limit of normal in serum (often > $1000 \mathrm{U} / \mathrm{l}$ ); then the parapneumonic effusion is called "complicated".

\section{MICROBIOLOGICAL EXAMINATION}

After obtaining fluid from the pleural cavity, the material should be microbiologically tested to detect pathogenic microorganisms $[3,6,9]$. If the presence of bacteria is confirmed, their sensitivity to antibiotics (antibiogram) is determined $[6,17]$. In the case of suspected tuberculous pleurisy, the fluid can also be examined for the presence of Mycobacterium tuberculosis [9, 23-25].

\section{CYTOLOGICAL EXAMINATION}

Cytological examination of pleural effusion is carried out to determine the type and number of morphotic cells and the possible presence of neoplastic cells [12]. In the exudate caused by Mycobacterium tuberculosis, there are an increased number of lymphocytes, while in other bacterial effusions an increased number of neutrophils is observed $[9,23]$. 


\section{TREATMENT OF PLEURAL EMPYEMA}

In 1918, Graham et al. established the principles of treatment of pleural empyema, which assumed the following: decompression of accumulated purulent content from the pleural cavity, efforts to early sterilise and overgrow the empyema cavity and improve the patient's nutritional status $[1,14,26]$. They remain unaltered. A significant improvement in the treatment of pulmonary infections and pleural empyema was caused by the introduction of antibiotic therapy in the 1940s $[1,6,14]$.

Currently, the three main principles of pleural empyema treatment are:

- evacuation of exudate from the pleural cavity,

- targeted antibiotic therapy,

- $\quad$ supportive treatment (physiotherapy, nutritional treatment, etc.) $[1,5,14]$.

In most cases of pleural empyema antibiotic therapy starts as empirical with broad-spectrum antibiotics [27, 28]. Penicillin combined with $\beta$-lactamase inhibitors and third-generation cephalosporins are most commonly used because of their good penetration of the pleural space $[6,27,28]$. In the case of reasonable suspicion of infection caused by atypical pathogens, macrolide antibiotics are indicated $[27,28]$. When suspected of methicillin-resistant Staphylococcus aureus infections, vancomycin or linezolid is required $[6,28]$. Broad-spectrum antibiotic therapy is continued until the presence of bacteria in pleural fluid or blood is confirmed and their sensitivity to antibiotics is determined, then targeted antibiotic therapy is administered [6, 27].

Debridement of the pleural cavity from purulent content, in addition to removing the infectious agent, results in lung expansion and improvement of lung ventilation $[5,14]$. This significantly influences on the shortening of the treatment time of the pulmonary-pleural infection, improves the general health condition, and allows quick recovery of the patient $[1,5,14,29-31]$. Techniques of decompression of the pleural cavity are: thoracentesis, pleural cavity drainage, and thoracoscopy $[3,6,14]$.

\section{THORACENTESIS}

The method combining the diagnosis and treatment is puncture of the pleural cavity (thoracentesis, thoracocentesis, pleural aspiration). It allows the decompression of fluid accumulation from the pleural cavity and gives material for further biochemical, bacteriological, and cytological examination $[3,9,14]$. This procedure should be performed in a hospital environment with the principles of asepsis [32]. Incompetent pleural puncture can lead to serious complications, such as:

- injury of the intercostal neurovascular bundle,

- pneumothorax due to mechanical lung injury,

- formation of a bronchopleural fistula,

- bleeding into the pleural cavity (haemothorax),
- injury of the diaphragm, liver, or spleen in the case of incorrect selection of the puncture place,

- acute circulatory failure caused by fast decompression of a large amount of fluid from the pleural cavity $[3,4,32]$.

Thoracentesis may be performed under local anaesthesia; however, in children it should be performed in sedation and analgesia due to limited cooperation of the patient $[14,32]$. In the case of punctures for fluid decompression, the puncture is usually performed in the sixth or seventh intercostal space in the mid or posterior axillary line [32]. In doubtful cases, the puncture can be performed under ultrasound control $[3,14,32]$. To avoid injury of the intercostal vessels, the puncture needle should be inserted on the upper edge of the rib [32]. The insertion of the needle should be continued until perceptible puncture of the pleural wall. Fluid aspiration confirms the correct position of the needle. Attention must be paid to the depth at which the puncture needle is inserted into the pleural cavity, to avoid lung injuries (a patch, a drain tube, a surgical instrument, or a second hand can be used) [32]. Currently, also prepared kits for puncture of the pleural cavity are available.

\section{DRAINAGE OF THE PLEURAL CAVITY}

Indications for drainage performance, place of insertion of the drain, and possible complications are similar to those of pleural cavity puncture [3, 9]. Drainage is usually inserted in the case of suspected purulent fluid, presence of large amounts of effusion, co-occurring pneumothorax, or in the absence of success of treatment with repetitive pleural punctures $[3,9]$. In children, this procedure is usually performed under general anaesthesia, although in older patients it is possible to perform the procedure under local anaesthesia.

The drain is placed into the pleural cavity using basic surgical instruments (scalpel, tweezers, preparation forceps) [32]. After the incision of the skin, a channel in the intercostal space should be prepared, through which the drain will be inserted. Afterwards, insert the forceps into the pleural cavity and place the end of the drain through the prepared canal; the drain is slid in to the appropriate depth [32]. An alternative is a specially prepared kit, in which the drain is connected to the trocar (Fig. 2).

It is important to properly fix the drain, to prevent movements and avoid its spontaneous removal [32]. After inserting the drain into the pleural cavity, it should be connected to a bottle drainage system or to a chest tube drainage system and then connected to a suction source (if suction drainage is required) or left as an underwater seal drainage $[6,32]$. In many hospitals drainage of the pleural cavity is still the basic method of pleural empyema treatment, especially in its early stage $[1,3,6,33]$. However, in the case of an advanced stage of disease, classical pleural cavity drainage may be ineffective $[1,3,6,33,34]$. 

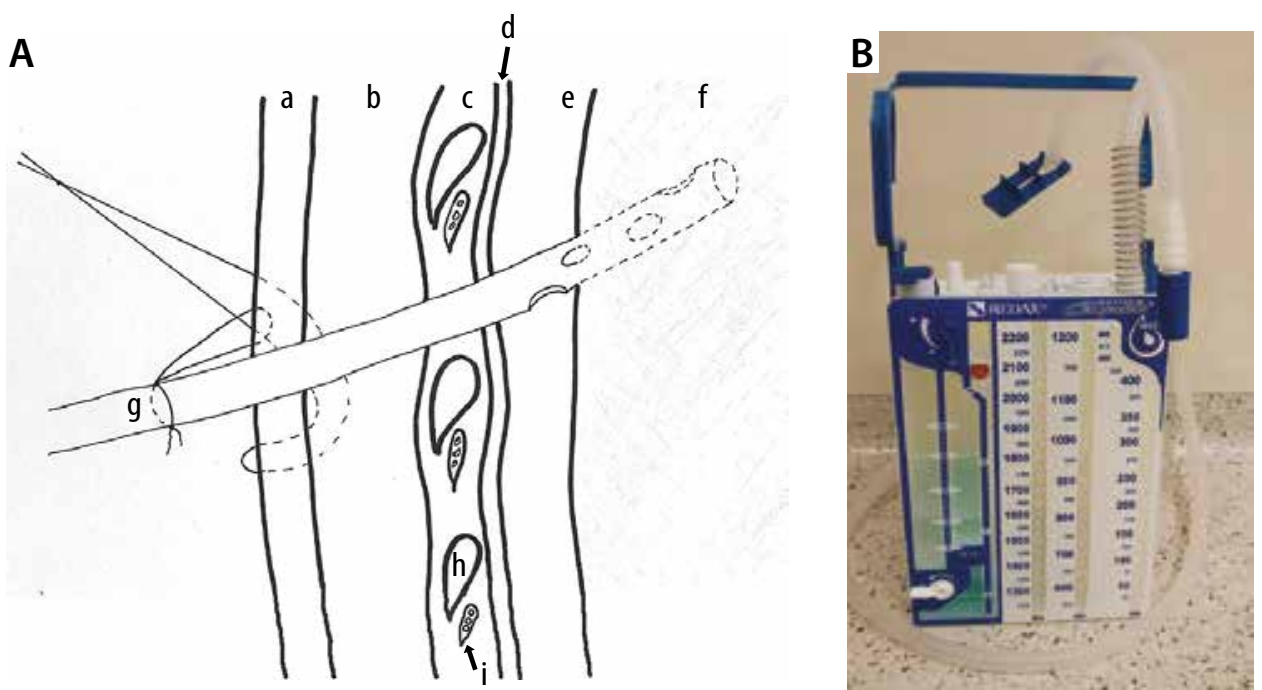

FIGURE 2. Drainage of the pleural cavity. A) Proper insertion of the pleural drainage (a - skin, b - subcutaneous tissue, c - chest wall, $\mathrm{d}$ - parietal pleura, $\mathrm{e}$ - empyema cavity, $\mathrm{f}$ - lung, $\mathrm{g}$ - drain tube, $\mathrm{h}$ - rib, $\mathrm{i}$ - intercostal neurovascular bundle). B) Chest tube drainage system

It is usually caused by the presence of dense purulent secretion, accumulation of fibrin layers, and the formation of septations and loculations $[1,3,6]$.

\section{THORACOSCOPY}

In recent years, the use of early thoracoscopic intervention in the treatment of pleural empyema has been growing in popularity [33-37]. The introduction of the thoracoscope to the pleural cavity enables precise assessment of the empyema, separation of septations and connection of the empyema loculations, evacuation of purulent content, pleural stratifications and fibrin conglomerates, as well as lung decortication $[3,35,37,38]$. Other advantages of thoracoscopy include the possibility of precise placement of the drain tube under optical control and collection of specimens for histopathological examination, which in some cases accelerates the diagnosis and allows effective treatment (e.g. in tuberculosis) $[1,9,23,25,37]$. Thoracoscopy in first and second stage of empyema is a procedure of low invasiveness, is relatively technically simple, and has risk comparable to classical pleural cavity drainage $[1,34,39]$. In advanced cases, thoracoscopy allows for efficient partial or total lung decortication, which results in improvement of respiratory movements [1, 34, 37, 38, 40]. Minimal invasiveness of the method encourages an earlier decision about the implementation of surgical intervention, because the best results of treatment are obtained in the early stages of the disease [1, 22, 27, 33-35, 37-39, 41].

The thoracoscopic procedure is performed with the patient lying on the side opposite to the one affected with pleural empyema $[35,36]$. The place of insertion of trocars is determined by analysis of chest radiograph, computed tomography, and ultrasound examination results $[27,35,36]$. First, an optical trocar is inserted, which is usually introduced through the sixth or seventh intercostal space in the mid or posterior axillary line (Fig. 3) [35].

After the incision of the skin, the muscles should be stratified, and then the preparative forceps should be inserted into the pleural cavity, after which the thoracoport or a typical laparoscopic trocar is introduced to the pleural cavity [35]. Sufficient operational space is achieved by producing positive pressure in the pleural cavity by carbon dioxide insufflation. Afterwards the thoracoscope is introduced through the optical trocar, which allows inspection of the empyema loculation $[27,35]$. After the optical control of the pleural cavity (Figs. 4A-4C), an exact clearance can be performed, consisting of the evacuation of accumulated purulent fluid and fibrin stratifications, separation of adhesions, and connection of empyema loculations, which gives improvement of respiratory movement $[27,35,36]$. In cases of significant progression of the disease process, when it is necessary to perform lung decortication, and when access to all the empyema loculations from one trocar is difficult, it is possible to introduce a second (and possibly third) instrumental trocar [35]. Thoracoscopy enables purulent content to be obtained for bacteriological examinations as well as fibrin stratification and pleural specimens for histopathological examination (Figs. 4D, 4E) $[27,34,35]$. A drain tube can be

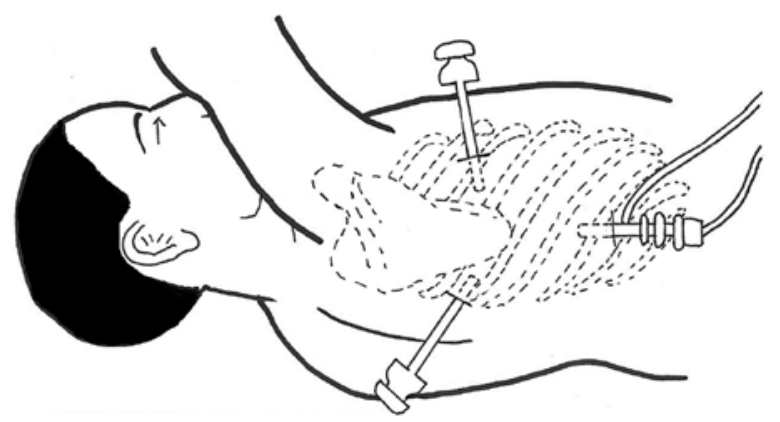

FIGURE 3. Typical arrangement of optical and instrumental trocars 

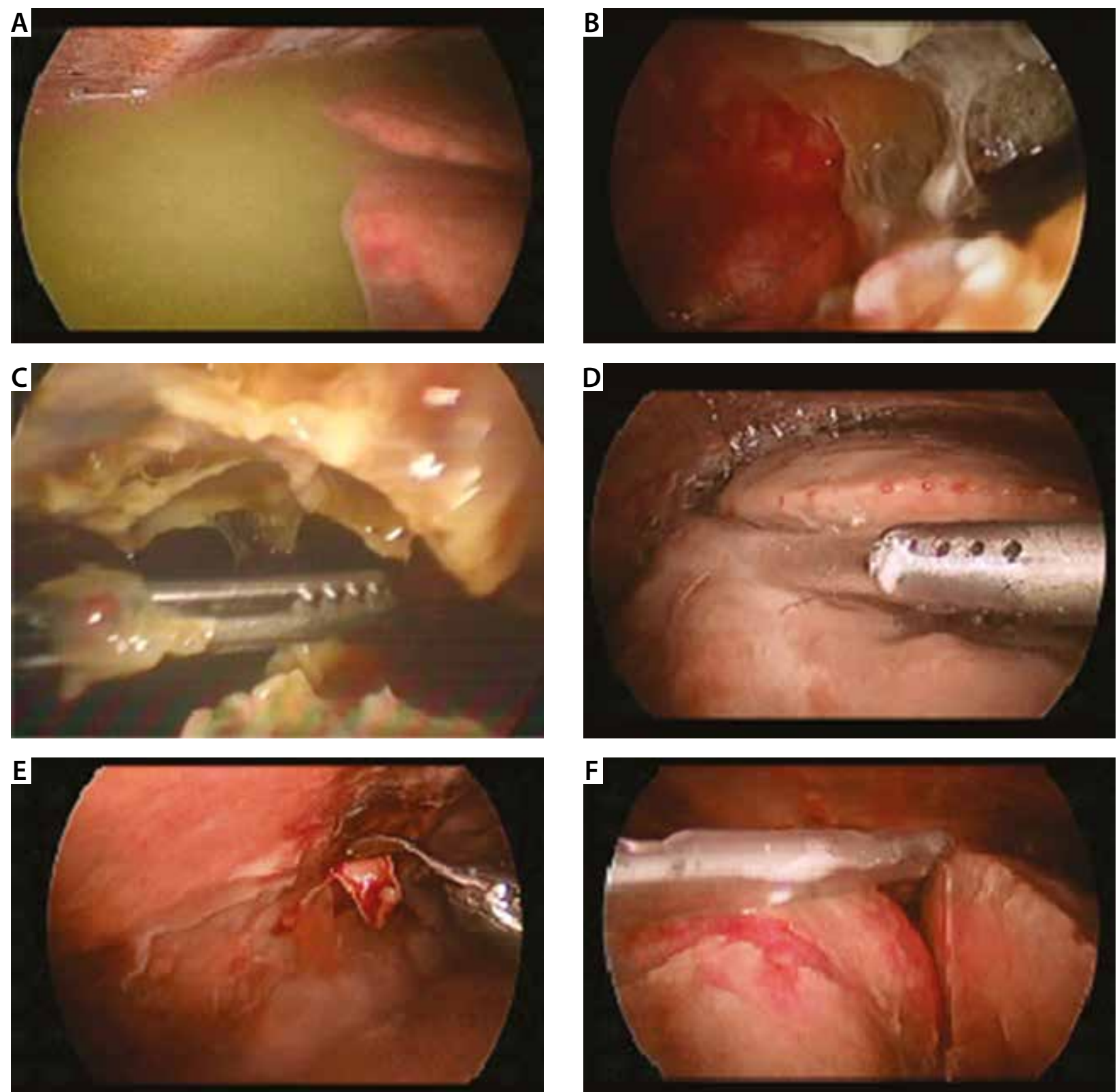

FIGURE 4. Intraoperative images: A) empyema in the $1^{\text {st }}$ stage, B) empyema in the $2^{\text {nd }}$ stage, C) empyema in the $3^{\text {rd }}$ stage, D) lavage of pleural cavity, E) pleural biopsy, F) placement of drain tube under optical control

placed in the pleural cavity under optical control (Fig. 4F) $[27,35,37]$.

\section{FIBRINOLYSIS}

In the case of abundant stratification of fibrin in the pleural cavity, there is the possibility of including intrapleural fibrinolytic therapy [15, 42-45]. For this purpose, the system of two drains can be placed in the pleural cavity, which allows repetitive lavage of the pleural cavity. The first generation of fibrinolytics are streptokinase, streptodornase, urokinase, and distreptase (a mixture of the enzymes streptokinase and streptodornase). Recently, the tissue activator of fibrinogen, alteplase, also has a great appreciation $[9,42]$. Fibrinolytics are administered every 24 hours ( $4 \mathrm{mg}$ of tissue plasminogen activator in $40 \mathrm{ml}$ of saline) [15] with closing the decompressive drain tube for 1-2 hours [42]. It has been proven in randomised controlled trials that treatment with pleural drainage and fibrinolysis is as effective as video-assisted thoracic surgery debridement [15]. The combination of these two therapeutic methods could be more effective, especially in severe (III stage) pleural empyema. Fibrinolytic therapy can be more effective if it is preceded by mechanical decortication of thick pleural fibrin stratifications, and the combination of thoracoscopic technique with subsequent intrapleural fibrinolysis can significantly improve the effects of treatment [35, 43, 46-49]. Fibrinolysis might be continued for 3-6 doses [42, 44, 45].

\section{OPEN THORACOTOMY WITH PLEURECTOMY}

Due to the increasing availability of the minimally invasive thoracoscopic method, open pleurectomy and 
extensive decortication is currently finding less use in the treatment of pleural empyema $[8,31,33,35,39,41$, $50-52]$. Even in cases with significant progression of the disease process with the formation of thick pleural stratifications and development of fibrothorax, the necessity of intervention via thoracotomy is currently extremely rare $[8,9,35,36,50,53]$. Also, with the coexistence of bronchopleural fistulas or necrotic and cirrhotic lesions of the lung, resulting in the necessity of resection of pulmonary tissue, this procedure is performed with an increasing frequency using the thoracoscopic method, which is less inconvenient for the patient $[8,35,36,39,47,51,54]$.

\section{CONCLUSIONS}

The primary treatment of pleural empyema is the implementation of appropriate antibiotic therapy and debridement of the pleural cavity from accumulated inflammatory content - effusion or pus. It should be emphasised that the use of drainage for this purpose is a correct method of treatment and is still the basic method of pleural cavity decompression. Current technical capabilities and the increasing experience of surgical teams allow early implementation of thoracoscopy, which definitely increases the efficiency of debridement of the pleural cavity, especially in the case of multiloculated fluid collection. Fibrinolytic therapy may improve treatment outcomes, especially in advanced cases. Interdisciplinary cooperation and the implementation of appropriate treatment (paediatric, pulmonological, physiotherapeutic, and in some cases intensive respiratory therapy) is extremely important.

\section{DISCLOSURE}

The authors declare no conflict of interest.

\section{REFERENCES}

1. Korlacki W. Nabyte schorzenia płuc i opłucnej. In: Chirurgia dziecięca, Bagłaj M, Kaliciński P (eds.). PZWL, Warszawa 2016; 328-331.

2. Grijalva CG, Zhu Y, Nuorti JP, et al. Emergence of parapneumonic empyema in the USA. Thorax 2011; 66: 663-668.

3. Redden MD, Chin TY, van Driel ML. Surgical versus non-surgical management for pleural empyema. Cochrane Database Syst Rev 2017; 3: CD010651.

4. Hyeon Y. Management of Pleural Effusion, Empyema, and Lung Abscess. Semin Intervent Radiol 2011; 28: 75-86.

5. Proesmans M, De Boeck K. Clinical practice: treatment of childhood empyema. Eur J Pediatr 2009; 168: 639-645.

6. Krenke K. Płyn w jamie opłucnej. In: Pediatria, tom I, Kawalec W, Grenda R, Ziółkowska H (eds.). PZWL, Warszawa 2013; 309-312.

7. Heffner JE, Klein JS, Hampson C. Interventional Management of Pleural Infections. Chest 2009; 136: 1148-1159.

8. Chambers A, Routledge T, Dunning J, et al. Is video-assisted thoracoscopic surgical decortication superior to open surgery in the management of adults with primary empyema? Interact Cardiovasc Thorac Surg 2010; 11: 171-177.

9. Yang W, Zhang B, Zhang ZM. Infectious pleural effusion status and treatment progress. J Thorac Dis 2017; 9: 4690-4699.

10. Almaramhy HH, Allama AM. Indicators for surgical intervention in thoracic empyema in children. Saudi Med J 2015; 36: 1061-1066.

11. Bochenek A, Reicher M. Opłucna. In: Anatomia człowieka, tom II. Bochenek A, Reicher M. PZWL, Warszawa 2015; 451-470.

12. Saguil A, Wyrick K, Hallgren J. Diagnostic Approach to Pleural Effusion. Am Fam Physician 2014; 90: 99-104.

13. Koppurapu V, Meena N. A review of the management of complex para-pneumonic effusion in adults. J Thorac Dis 2017; 9: 2135-2141.

14. Davies HE, Davies RJ, Davies CW. Management of pleural infection in adults: British Thoracic Society pleural disease guideline 2010. Thorax 2010; 65 (Suppl 2): ii 41-53.

15. St Peter SD, Tsao K, Spilde TL, et al. Thoracoscopic decortication vs tube thoracostomy with fibrinolysis for empyema in children: a prospective, randomized trial. J Pediatr Surg 2009; 44: 106-111.

16. Blaschke AJ, Heyrend C, Byington CL, et al. Molecular analysis improves pathogen identification and epidemiologic study of pediatric parapneumonic empyema. Pediatr Infect Dis J 2011; 30: 289-294.

17. Lisboa T, Waterer GW, Lee YC. Pleural infection: changing bacteriology and its implications. Respirology 2011; 16: 598-603.

18. Krenke K, Sadowy E, Podsiadły E, et al. Etiology of parapneumonic effusion and pleural empyema in children. The role of conventional and molecular microbiological tests. Respir Med 2016; 116: 28-33.

19. Suárez PR, Gilart JF, Hernández Pérez JM, et al. Treatment of complicated parapneumonic pleural effusion and pleural parapneumonic empyema. Med Sci Monit 2012; 18: CR443-CR449.

20. Tsujimoto N, Saraya T, Light RW, et al. A Simple Method for Differentiating Complicated Parapneumonic Effusion/Empyema from Parapneumonic Effusion Using the Split Pleura Sign and the Amount of Pleural Effusion on Thoracic CT. PLoS One 2015; 10 : e0130141.

21. Medeiros IL, Terra RM, Choi EM, et al. Evaluation of serial C-reactive protein measurements after surgical treatment of pleural empyema. Clinics 2012; 67: 243-247.

22. Light RW, Rodriguez RM. Management of parapneumonic effusions. Clin Chest Med 1998; 19: 373-382.

23. Keys C, McLeod E, Pesti C, et al. Thoracoscopic pleural biopsy as an aid to diagnosis in pediatric tuberculosis with pleural involvement. Eur J Pediatr Surg 2012; 22: 315-317.

24. Singh AP, Shukla AK, Sharma P, et al. Surgical management of stage III pediatric empyema thoracis. Lung India 2018; 35: 209-214.

25. Pasierbek M, Korlacki W, Grabowski A, et al. The role of thoracoscopy in the diagnosis of pleurisy. Pediatr Pol 2018; 92: 681-686.

26. Hiram T, Langston MD, Graham EA. Empyema Thoracis. Ann Thorac Surg 1966; 2: 766-768.

27. Tassi GF, Marchetti GP, Pinelli V, et al. Practical management of pleural empyema. Monaldi Arch Chest Dis 2010; 73: 124-129.

28. Harris M, Clark J, Coote N, et al. British Thoracic Society guidelines for the management of community acquired pneumonia in children: update 2011. Thorax 2011; 66 (Suppl 2): ii1-23.

29. Cohen E, Weinstein M, Fisman DN. Cost-effectiveness of Competing Strategies for the Treatment of Pediatric Empyema. Pediatrics 2008; 121: 1250-1258.

30. Shah SS, Ten Have TR, Metlay JP. Costs of Treating Children With Complicated Pneumonia: A Comparison of Primary Video-Assisted Thoracoscopic Surgery and Chest Tube Placement. Pediatr Pulmonol 2010; 45: 71-77.

31. Scarcia M, Zahidb I, Billéa A, et al. Is video-assisted thoracoscopic surgery the best treatment for paediatric pleural empyema? Interact Cardiovasc Thorac Surg 2011; 13: 70-76. 
32. Havelock T, Teoh R, Laws D, et al. Pleural procedures and thoracic ultrasound: British Thoracic Society pleural disease guideline 2010. Thorax 2010; 65: i61-i76.

33. Elsayed HH, Mostafa A, Fathy E, et al. Thoracoscopic management of early stages of empyema: is this the golden standard? J Vis Surg 2018; 4: 114-120.

34. Wozniak CJ, Paull DE, Moezzi JE, et al. Choice of first intervention is related to outcomes in the management of empyema. Ann Thorac Surg 2009; 87: 1525-1531.

35. Wait MA, Beckles DL, Paul M, et al. Thoracoscopic management of empyema thoracis. J Minim Access Surg 2007; 3: 141-148.

36. Tsao K, St. Peter SD, Sharp SW. Current Application of Thoracoscopy in Children. J Laparoendosc Adv Surg Tech 2008; 18: 131-135.

37. Ravaglia C, Gurioli C, Tomassetti S, et al. Is Medical Thoracoscopy Efficient in the Management of Multiloculated and Organized Thoracic Empyema? Respiration 2012; 84: 219-224.

38. Hajjar WM, Ahmed I, Al-Nassar SA, et al. Video-assisted thoracoscopic decortication for the management of late stage pleural empyema, is it feasible? Ann Thorac Med 2016; 11: 71-78.

39 Meier AH, Hess CB, Cilley RE. Complications and treatment failures of video-assisted thoracoscopic debridement for pediatric empyema. Pediatr Surg Int 2010; 26: 367-371.

40. Vaziri M, Abed O. Management of thoracic empyema: review of 112 cases. Acta Med Iran 2012; 50: 203-207.

41. Stefani A, Aramini B, della Casa G, et al. Preoperative predictors of successful surgical treatment in the management of parapneumonic empyema. Ann Thorac Surg 2013; 96: 1812-1819.

42. Alema C, Porcel JM, Alegre J, et al. Intrapleural Fibrinolysis with Urokinase Versus Alteplase in Complicated Parapneumonic Pleural Effusions and Empyemas: A Prospective Randomized Study. Lung 2015; 193: 993-1000.

43. Rahman NM, Maskell NA, West A, et al. Intrapleural use of tissue plasminogen activator and DNase in pleural infection. N Engl J Med 2011; 365: 518-526.

44. Idell S, Florova G, Shetty S, et al. Precision-guided, Personalized Intrapleural Fibrinolytic Therapy for Empyema and Complicated Parapneumonic Pleural Effusions: The Case for the Fibrinolytic Potential. Clin Pulm Med 2017; 24: 163-169.

45. Huggins JT, Doelken P, Sahn SA. Intrapleural therapy. Respirology 2011; 16: 891-899.

46. Safiyeh M, Huang D. New strategies to manage complicated pleural effusions. Crit Care 2012; 16: 312.

47. Bishay M, Short M, Shah K, et al. Efficacy of video-assisted thoracoscopic surgery in managing childhood empyema: a large singlecentre study. J Pediatr Surg 2009; 44: 337-342.

48. Colice L, Idell S. Counterpoint: should fibrinolytics be routinely administered intrapleurally for management of a complicated parapneumonic effusion? No. Chest 2014; 145: 17-20.

49. Metin M, Yeginsu A, Sayar A, et al. Treatment of multiloculated empyema thoracis using minimally invasive methods. Singapore Med J 2010; 51: 242-246.

50. Cardillo G, Carleo F, Carbone L, et al. Chronic postpneumonic pleural empyema: comparative merits of thoracoscopic versus open decortication. Eur J Cardiothorac Surg 2009; 36: 914-918.

51. Shahin Y, Duffy J, Beggs D, et al. Surgical management of primary empyema of the pleural cavity: outcome of 81 patients. Interact Cardiovasc Thorac Surg 2010; 10: 565-567.

52. Casali C, Storelli ES, Di Prima E, et al. Long-term functional results after surgical treatment of parapneumonic thoracic empyema. Interact Cardiovasc Thorac Surg 2009; 9: 74-78.
53. Tong BC, Hanna J, Toloza EM, et al. Outcomes of video-assisted thoracoscopic decortication. Ann Thorac Surg 2010; 89: 220-225.

54. Terra RM, Waisberg DR, Almeida JL, et al. Does videothoracoscopy improve clinical outcomes when implemented as part of a pleural empyema treatment algorithm? Clinics 2012; 67: 557-564. 